\title{
Air Quality in Welding Workshops and Its Health Implication on Welders in Port Harcourt
}

\author{
Chukwu Okeah $\mathrm{GO}^{1 *}$, Igwe $\mathrm{A}^{2}$, Mmom $\mathrm{PC}^{3}$ and Eze $\mathrm{A}^{3}$ \\ ${ }^{1}$ Department of Geography \& Environmental Management, University of Port Harcourt, Nigeria \\ ${ }^{2}$ Environmental Consultant, Port Harcourt, Nigeria \\ ${ }^{3}$ Centre for Disaster Risk Management and Development Studies, University of Port Harcourt, Nigeria
}

Received: 眥 March 19, 2018; Published: 眥 March 28, 2018

*Corresponding author: Chukwu Okeah GO, Department of Geography \& Environmental Management, University of Port Harcourt, Nigeria, Email: gift.chukwuokeah@uniport.edu.ng

\begin{abstract}
The study was carried out in Port Harcourt to ascertain the air quality status of air in welding workshops and the health implication on welders in Port Harcourt. Five objectives alongside five research questions were set to guide in the achievement of the aim of the study. The experimental and the cross sectional research design were adopted in carrying out this study. A total of 217 welders were sampled for the study out of a total of 496 registered welders in Port Harcourt. The probability sampling technique was used in determining the sample population for the study. Descriptive statistics was used in the analysis of the data collected from the respondents. The findings of the study revealed that the air quality in the welders shop does not meet internationally accepted standards, the use of personal protective equipments is still not in its full state hence endangering lives of the welders and that large number of welders have suffered from catarrh, cough, Heart ache, waist pain skin rashes and breathing difficulty. The study recommended that health is wealth; therefore if welders must be in optimal health conditions, occupational based illness must be reduced. On the basis of this health checks for every worker must be done quarterly to verify the health status of every welder as to reduce their health risk. It also recommended that there is need for quarterly air quality assessment to be done to assess the air quality status of the welder's worksite and then identify generators/sources of pollutants, so as to reduce their occurrence.
\end{abstract}

Keywords: Air quality; Welders; Welding workshop; Health

\section{Introduction}

Health is associated with the well being of an individual, which measures the extent to which a person is able to perform work and still remain in an optimal productive state. According to World Health Organization [1], health is a state of complete physical, mental, and social well-being and not merely the absence of disease or infirmity. Health can be threatened by a lot of risk factors depending on the kind of occupation and the level of exposure. The International Standards Organization (2009) identified risk as the potential that a chosen action or activity will lead to a loss. It also identified that every human endeavors carries some level of risk but that risk levels differ due to the type of occupation that is been carried out. Health and wellbeing are affected by different factors, and ill health, disability, disease or death has been identified as risk factors [2]. Risk factors as they posits, are noted on individual basis, while in practice there operate holistically and not in isolation since there co exist and are seen to have an interaction with one another. With recent trends in globalization, development and innovations, the industrial sector plays an important role in the achievement of industrialization which is the driving force on any nation's economy. In the process of production, welding plays an important role of providing the technology of joining, especially in the still manufacturing industries where it accounts for value creation, the production and manufacturing of ships, building bridges as well as offshore and onshore foundations for oil drilling operations (Cheng et al. 2015). The construction industry as put forth by Pinto, Nunes and Ribeiro [3] is a high employment generating sectors in many countries of the world. They stated that in the construction industry there is diversity of activities which workers perform and 
that each of these jobs comes with its attending risk associated with it. Hence the workers who carry out these responsibilities are directly exposed to the associated risk posed by the job as well as those done by their co workers who are close by.

Welding as a production activity has been known to be a powerful manufacturing tool that provides the services of highquality joining of metals [4]. Basically, all metals and alloys can be welded both with ease and special methods which also requires high level precautions. According to the American Welding Society, there are about 80 identified types of welding and allied processes that are in use commercially. Of these 80 identified welding types each method has its own particular metallurgical and operational advantages, with its associated potential health and safety hazard. Hence, the welders as a group of persons related by occupation are not a homogeneous group, since they work under different conditions such as outdoors, indoors in open as well as confined spaces, underwater, and above ground on construction sites, which entails the use of several welding and cutting processes. Globally, there is evidence that most welders are exposed to the welding fumes as the work as welders in their work place where welding, fabrication and the joining of metal parts are performed. Crawford [5] identified that welding fumes are carcinogenic in nature, hence have the ability to cause harm to human health. This therefore explains that exposure to welding fumes is a risk.

In Nigeria, there is evidence of inadequate awareness of health risk assessment, this is because it is seen as an emerging are of study (Nigerian Institute of Safety Professional (NISP), [6]). On the basis of this, much attention is paid to safety precautions rather than a comprehensive quarterly, annual or bi annual health risk assessment which would provide information on the health status of a person in relation to the type of work as well as the hazard to which they are exposed so as to provide preventive measures as well as predict the outcome of continuous exposure to such working environment, Hence medical test are being compromised for purposes of physical fitness to work and this on the long run has led to high morbidity rate, accidents and low productivity. It is worthy of note that welding processes needs high energy and resources, and discharges a large amount of fumes which are of very prominent health implication on welders, therefore there is a need to examine the health risk associated with these class of reasons as to quantify the potential effects on health of welders, which available literature within the study area has not addressed.

\section{Methods}

The study is a survey/experimental research hence; it allowed for the adoption of two types of data collection approach. The study therefore allowed for the use of questionnaire and field studies (experimental). On the basis of the objectives of the study which entails to identify the current practices of the welders in Port Harcourt and find out the status of the equipment's that are used in the work places in line with posing health challenges. A structured questionnaire was used to achieve this, as it concentrated on the type of welding prevalent in the area, level of use of Personal protective equipment, types of accidents that have ever occurred arising from the welding occupation, ergonomics, length of time spent on the job, types of illnesses that the welders have suffered from over the years, number of visits to the hospital in the last six months, amounts spent on health in the hospital in the last six months. All these aspects were achieved through the use of the questionnaire. Therefore 217 copies of questionnaires were administered to the respondents (welders).

The aspect of ascertaining the level of exposure to risk in the welding shops using air quality measurements and the World Health Organization standards for air quality was done using the Portable Real-Time Monitoring Technique which was used to determine ambient air (outdoor- breathing zone) in the welding site because ambient air monitoring characterizes levels of pollution in the air that people breathe, and usually provides the best measure for air exposure concentrations in the vicinity of the welders working areas (ATSDR, 2001). Air samples were automatically analyzed for Nitrogen oxides ( $\mathrm{NO}$ and $\mathrm{NO}_{2}$ ), Oxides of carbon (CO), Sulphur dioxide $\left(\mathrm{SO}_{2}\right)$, Ozone $\left(\mathrm{O}_{3}\right)$ and Particulate Matter (PM) content. Data for these gases was achieved using the BW Gas Alert Micro 5 IR (Plate 1).

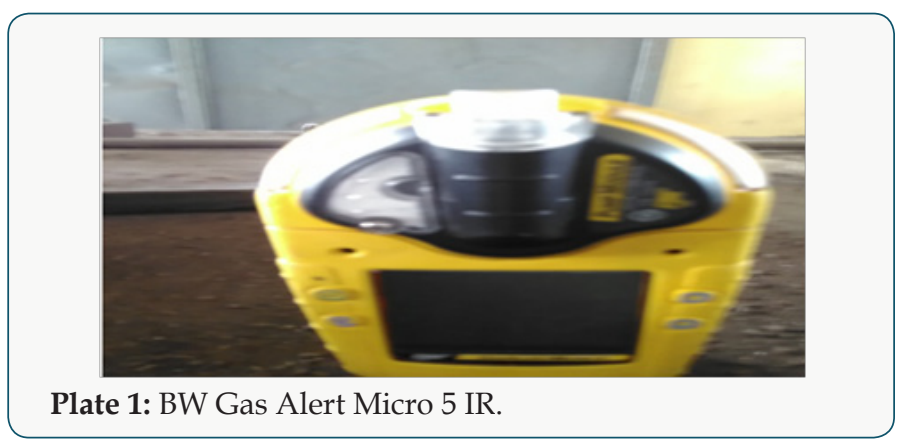

Ozone was determined using the S-200 Portable Ozone monitor (Plate 2).

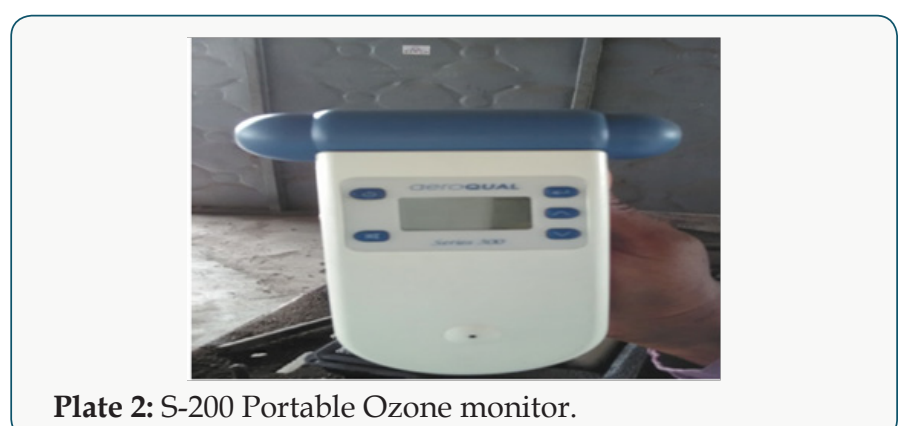

The instruments was powered on and placed within the breathing zone in the worksite in the direction of the prevailing wind. Gas concentration reading was then taken off the instrument's monitor. Particulate Matter (PM) was collected using the Met One GT-531 Hand Held Particle Counter measuring five ranges of Total Suspended Particles: 1, 2.5, 5, 7and 10 micron size ranges in Milligrams per Cubic metre $\left(\mathrm{mg} / \mathrm{m}^{3}\right)$ (Plate 3$)$. 


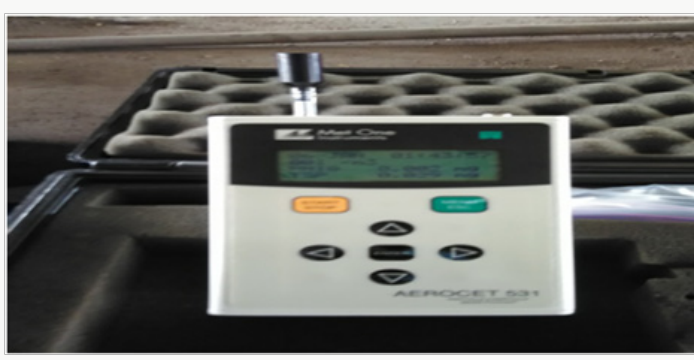

Plate 3: Met One GT-531 Hand Held Particle Counter.

The sampler takes a total of 10 samples for each micron size after which it averages them to represent the result per micron size per location. The particulate monitor was placed at a considerable distance above ground level, within the breathing zone, switched on in the environment of interest and the measured concentration read directly on the screen after particle capturing.

The place of noise in relation to the health of welders was also considered in the study; therefore the noise meter was used to measure the noise level in the welder's shop as to determine the health implication of excessive noise on the health of the welders. The Cole-Parmer Extech Model 407730 sound level meter was used for collecting noise levels. The 407730 measures and displays sound pressure levels in $\mathrm{dB}$ from 40 to $130 \mathrm{~dB}$. The meter was powered and held away from the body and with the windscreen placed over the microphone; sound level readings was then taken from the display monitor in decibels $(\mathrm{dB})$ in welder's shop (Plate 4).

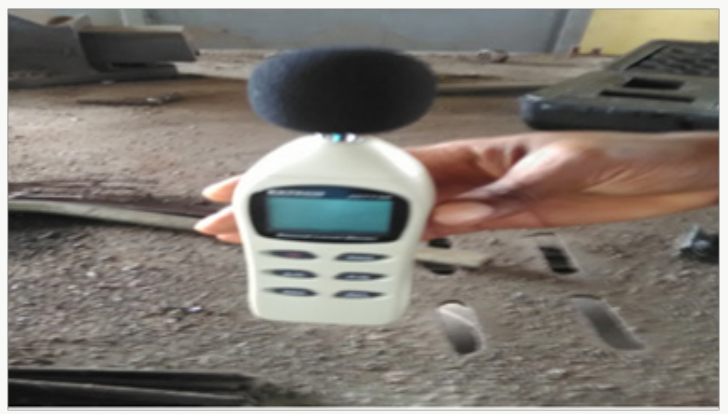

Plate 4: The Cole-Parmer Extech Model 407730 sound level meter.

Table 3: Average Particulate Matter Spread in Welding Worksite.

\begin{tabular}{|c|c|c|c|c|c|}
\hline Particulate Matter & PM1 $\left(\mathbf{m g} / \mathbf{m}^{3}\right)$ & PM2.5 $\left(\mathbf{m g} / \mathbf{m}^{3}\right)$ & PM5 $\left(\mathbf{m g} / \mathbf{m}^{3}\right)$ & PM7 $\left(\mathbf{m g} / \mathbf{m}^{3}\right)$ & PM10 $\left(\mathbf{m g} / \mathbf{m}^{3}\right)$ \\
\hline 1 & 0.0022 & 0.01043333 & 0.03 & 0.03583333 & 0.0454 \\
\hline
\end{tabular}

As revealed from (Table 4) above, using the World health Organization (2016) facts finding document on ambient air quality adapted from the WHO Air quality guidelines for particulate matter, ozone, nitrogen dioxide and sulfur dioxide, Global update [9]. It is revealed that in the welders work site sulphur dioxide measured $0.129667 \mathrm{mg} / \mathrm{m}^{3}$, while the WHO standard is 0.02 which is below the actual value of sulphur dioxide found in the welder's worksite. This therefore reveals that sulphur dioxide in the welders worksite is above the WHO acceptable standard, hence can pose serious
The choice for these equipments is that at the time of this study within the knowledge of the researcher, these were the ones that were available for this monitoring owing to the nature of the pollutants which focuses on gases, dust particle and noise of which a personal sampler cannot be able to detect all in one. Moreso, studies in this part of the world has proven the efficacy of this equipment in the measurement of air pollutants within a fertilizer plant, which assessed the risk of exposure to pollutants from fertilizer production (Ochindo, [7]), it has also been used in air quality studies in a cement production factory as put forth by Akajiaku [8].

These independent studies have shown that to a great extent the methodology and equipments stated above, are appropriate for a study such as this.

\section{Results}

\section{Air quality report}

(Table 1), From the table it is shown that, average noise level is $87.6 \mathrm{db}$ and temperature level is $27.30 \mathrm{C}$ in the worksite.

Table 1: Average Noise and Temperature level in Welding worksite.

\begin{tabular}{|l|c|c|}
\hline 1 & Noise & 87.6 \\
\hline 2 & Temperature & 27.3 \\
\hline
\end{tabular}

(Table 2) As revealed on table two above, the measured gases showed that within the welding worksite Ozone is $62.1 \mathrm{mg} /$ $\mathrm{m} 3$, Nitrogen Oxide is $0.1680667 \mathrm{mg} / \mathrm{m}^{3}$, Sulphur dioxide is $0.1296667 \mathrm{mg} / \mathrm{m}^{3}$, and Carbon monoxide recorded $11.0553 \mathrm{mg} / \mathrm{m}^{3}$.

Table 2: Average Air Quality in Welding Worksite.

\begin{tabular}{|c|c|c|c|c|}
\hline $\begin{array}{c}\text { Air Quality } \\
\text { Parameters }\end{array}$ & $\mathbf{O}^{\mathbf{3}}$ & $\begin{array}{c}\mathbf{N O}^{2} \mathbf{( m g} / \\
\left.\mathbf{m}^{3}\right)\end{array}$ & $\begin{array}{c}\mathbf{S O}^{2} \mathbf{( m g} / \\
\mathbf{m} 3)\end{array}$ & $\begin{array}{c}\mathbf{C O}(\mathbf{m g} / \\
\left.\mathbf{m}^{3}\right)\end{array}$ \\
\hline 1 & 0.03 & 0.1680667 & 0.1296667 & 11.0553 \\
\hline
\end{tabular}

(Table 3), As shown on the table, PM1 in the worksite is $0.0022 \mathrm{mg} / \mathrm{m}^{3}$ PM2 is $0.01043 \mathrm{mg} / \mathrm{m}^{3}$ PM7 the average also accounted for $0.0358 \mathrm{mg} / \mathrm{m}^{3}$ and PM10 accounted for $0.0454 \mathrm{mg} /$ $\mathrm{m}^{3}$.

danger to life of the welders in the worksite. Nitrogen dioxide as revealed showed that its value of $0.1680667 \mathrm{mg} / \mathrm{m}^{3}$ in the welder's worksite is above the WHO permissible limit value of $0.04 \mathrm{mg} / \mathrm{m}^{3}$.

Carbon monoxide (CO) as revealed from the welder's worksite is $11.0553 \mathrm{mg} / \mathrm{m}^{3}$ while WHO standard is $10.0 \mathrm{mg} / \mathrm{m}^{3}$; this justifies that (CO) value from the welders worksite is above the WHO permissible limit. The measurement for Ozone revealed that the measured value of 0.03 is higher than the WHO standard of 0.1 . 
Table 4: Air Quality Parameters and WHO Standard.

\begin{tabular}{|c|c|c|}
\hline Parameters & Values/ Readings & WHO, 2016 \\
\hline $\mathrm{SO}_{2}\left(\mathrm{mg} / \mathrm{m}^{3}\right)$ & 0.1296667 & 0.02 \\
\hline $\mathrm{NO}_{2}\left(\mathrm{mg} / \mathrm{m}^{3}\right)$ & 0.1680667 & 0.04 \\
\hline $\mathrm{CO}\left(\mathrm{mg} / \mathrm{m}^{3}\right)$ & 11.0553 & 10.0 \\
\hline $\mathrm{O}^{3}$ & 0.03 & 0.1 \\
\hline $\mathrm{PM}_{1}\left(\mathrm{mg} / \mathrm{m}^{3}\right)$ & 0.0022 & - \\
\hline $\mathrm{PM}_{2.5}\left(\mathrm{mg} / \mathrm{m}^{3}\right)$ & 0.01043333 & 0.01 \\
\hline $\mathrm{PM}_{5}\left(\mathrm{mg} / \mathrm{m}^{3}\right)$ & 0.03 & - \\
\hline $\mathrm{PM}_{7}\left(\mathrm{mg} / \mathrm{m}^{3}\right)$ & 0.03583333 & - \\
\hline $\mathrm{PM}_{10}\left(\mathrm{mg} / \mathrm{m}^{3}\right)$ & 0.0454 & 0.02 \\
\hline $\mathrm{Temperature}^{2}$ & 27.3 & - \\
\hline Noise & 87.6 & $85 \mathrm{db}$ \\
\hline
\end{tabular}

In the case of particulate matter, out of the five for which record was taken only two which are PM 2.5 and PM 10 were seen in the WHO standards as recorded in the WHO Air quality guidelines for particulate matter, ozone, nitrogen dioxide and sulfur dioxide, Global update [9]. From the (Table 3) PM 2.5 have a value of $0.01043333 \mathrm{mg} / \mathrm{m}^{3}$ from the welders worksite, but the WHO permissible limit reveal that only $0.01 \mathrm{mg} / \mathrm{m}^{3}$ is allowable. PM 10 also as revealed has a value of $0.0454 \mathrm{mg} / \mathrm{m}^{3}$ as measured from the welder's worksite, but the WHO standard reveals that only $0.02 \mathrm{mg} /$ $\mathrm{m}^{3}$ of PM 10 is allowable. Temperature value of 27.60 Celsius was recorded in the welders worksite although no standards was identified from WHO, but OSHA [10] states that temperature limits of 66-77 Fahrenheit which translates to 250 Celsius. In line with the OSHA standard, it can be deduced that that the temperature is still high hence could pose some level of risk to the welders. Noise level in the worksite recorded 87.6 decibel, the WHO standard did not specify for this category, hence in quest for identified standards because of the risk of noise level to human health, the World bank group Environmental, Health, and Safety (EHS) Guidelines General Ehs Guidelines: Occupational Health And Safety, [10] report showed that within industrial areas noise level of 85 decibel is allowable. The noise level in the worksite is still higher than this standard hence it therefore reveals that the welders with this level of noise are at risk [11].

(Table 5) revealed the use of Personal Protective Equipment in the worksite. The frequency of use of the personal protective equipment as shown in (Table 4) revealed that coverall was always used by only 128 respondents representing $58.9 \%$ of the study population; hence $47.1 \%$ of the study population did not use the coverall always as expected. The case of use of safety boot revealed that 217 respondents representing a $100 \%$ of the total study population in the worksite used safety boot always. The use of earmuff as revealed showed that 110 respondents representing $50.69 \%$ of the study population uses the ear muff once in a while. The use of hand glove revealed that 107 respondents representing $49.3 \%$ used the hand glove while working in the worksite regularly.
In the case of Helmet only 99 respondents representing $45.6 \%$ made use of it regularly, filling glass usage revealed that 45 respondents representing $20.7 \%$ of the total population used it always while working.

Table 5: Use of Personal Protective Equipment.

\begin{tabular}{|c|c|c|c|}
\hline \multirow{2}{*}{$\begin{array}{c}\text { Types of PPE } \\
\text { in use }\end{array}$} & \multicolumn{3}{|c|}{ Frequency of Use } \\
\cline { 2 - 4 } & Always & Not very often & Once in a while \\
\hline Coverall & 128 & 54 & 35 \\
\hline Safety Boot & 217 & - & 110 \\
\hline Ear muff & 45 & 62 & 45 \\
\hline Hand glove & 107 & 65 & 85 \\
\hline Helmet & 96 & 36 & 133 \\
\hline Filling glass & 45 & 39 & - \\
\hline Welding glass & 189 & 28 & 97 \\
\hline Nose mask & 97 & 23 & \\
\hline
\end{tabular}

The use of welding glass also revealed that 189 respondents representing $87.1 \%$ of the total study population always used it in the worksite, while nose mask usage as shown on (Table 6) revealed that 97 respondents representing $44.7 \%$ of the study population always used the nose mask working in the worksite.

(Table 6) shows welding and its health implication, from the analysis, it is observed that on the kinds of illness suffered by welders, 197 welders representing $90.7 \%$ of the study population consented that they have suffered catarrh while only 20 respondents representing $9.3 \%$ of the study population stated that they have not had catarrh. Cough as a kind of illness as indicated on the table, reveals that 199 respondents representing 91.7\% of the study population have suffered cough while 28 respondents representing $12.9 \%$ stated that they have not had any case of cough.

Table 6: Welding and Health.

\begin{tabular}{|c|c|c|c|c|c|c|}
\hline \multicolumn{4}{|c|}{ Kind of illness Suffered } & \multicolumn{2}{c|}{$\begin{array}{c}\text { Record of Lungs } \\
\text { Related illness }\end{array}$} & \multicolumn{2}{c|}{$\begin{array}{c}\text { Record of } \\
\text { Cancer/Heart } \\
\text { Related Illness }\end{array}$} \\
\hline \multirow{2}{*}{ Catarrh } & Yes & No & \multirow{2}{*}{ Yes } & No & Yes & No \\
\cline { 2 - 7 } & 197 & 20 & & & & 28 \\
\hline Cough & 199 & 28 & 169 & 48 & 189 & 28 \\
\hline Heart ache & 189 & 28 & & & & \\
\hline Waist Pain & 167 & 50 & & & & \\
\hline Skin Rashes & 159 & 58 & & & & \\
\hline $\begin{array}{c}\text { Breathing } \\
\text { difficulty }\end{array}$ & 201 & 16 & & & & \\
\hline
\end{tabular}

Heart ache revealed that only 189 representing $87.1 \%$ of the study population have suffered cough while 28 respondents representing $12.9 \%$ stated that they have not had any case of heart ache. Waist pain as revealed on the table shows that 167 respondents representing $76.9 \%$ of the study population have suffered waist pain while 50 respondents representing $23.1 \%$ stated that they have not had any case of waist pain. In the case 
of skin rashes, 159 respondents representing $73.3 \%$ of the study population have suffered skin rashes while 58 respondents representing $26.7 \%$ stated that they have not had any case of rashes. Lastly, difficulty in breathing as revealed on the table has been experienced by a large number of the respondents. 201 of the respondents representing $92.6 \%$ of the study population have had cases of breathing difficulties while 16 respondents representing $7.4 \%$ have not had any of such case. Lungs related illness shows that $77.8 \%$ of the study population has suffered it and in the case of cancer/heart related illness, $87.1 \%$ of the study population has suffered from it.

\section{Conclusion and Recommendations}

A cursory look at the findings of this study will acknowledge that welders are at risk sometimes borne out of their own negligence and other times as a result of the work environment. Hence the need for an efficient and effective work environment that will help reduce their exposure to risk and enhance their performance in the worksite, hence the following recommendations are made;

1. There is need for quarterly air quality assessment to be done to assess the air quality status of the worksite and then identify generators/sources of pollutants, so as to reduce their occurrence.

2. Also air dispersants use in worksites will enhance the quality of air. According to WHO [9] Clean air is considered to be a basic requirement of human health and well-being.

3. The use of power generating plants that are outdated needs to be discouraged. This is because there generate noise that creates hearing difficulty for the welders and adds to the pollution of the air, hence posing danger to human health.

4. The use of personal protective equipments by welders in the worksite needs to be critically reviewed. The use of personal protective equipments according to OSHA [10] is a vital component in the reduction of occupational hazards and health risk.

\section{References}

1. WHO (1998) Constitution of World Health Organization. Chronicle of WHO, $1,1$.

2. Achalu EI (1999) Nigeria's environmental problems and current legislative control. The action plan, Nigerian school Health Journal (1\&2): 112-134.

3. Abel Pinto, Isabel L Nunes, Rita A Ribeiro (2011) Occupational risk assessment in construction industry-Overview and reflection. Safety Science 49(5): 616-624.

4. Antonini JM (2003) Health effects of welding. Crit Rev Toxicol 33: 61103.

5. Crawford DF (2002) Rules of occupational Health risk assessment. Journal of Risk Assessment 3: 106-117. IARC 1990 IARC monographs on the evaluation of carcinogenic risks to humans, Chromium, nickel and welding. IARC (International Agency for Research on Cancer), Lyon, 49: pp. 677.

6. (1999) Nigerian Institute of Safety Professionals (NISP) Annual Bulletin.

7. Ochindo EO (2014) An Investigation of the Health risk associated with Air Quality impacts from Fertilizer Manufacturing in Onne, Rivers State. An Unpublished MSc Thesis. Centre for Disaster Risk Management and Development Studies, University of Port Harcourt, Nigeria.

8. Akajiaku UC (2015) Analysis of the Impact of Cement Production on Air Quality and Health of Residents around Dangote Cement Factory, Onne. An Unpublished M.sc Thesis, University of Port Harcourt, Nigeria.

9. (2005) WHO Air quality guidelines for particulate matter, ozone, nitrogen dioxide and sulfur dioxide. Global Update 2005 Summary of risk assessment.

10. (2007) Occupational Safety and Health Administration. Safety and Health Topic Criteria for a Recommended Standard: Working in Confined Spaces. Occupational Safety \& Health Administration, Washington, USA.

11. Ching WuCheng, Sou Sen Leu, Chen Chung Lin, Chihhao Fan (2010). Characteristic analysis of occupational accidents at small construction enterprises. Safety Science 48(6): 698-707.

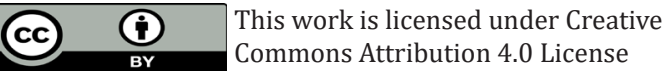

To Submit Your Article Click Here: Submit Article

DOI: $10.32474 /$ AOICS.2018.02.000138

\section{AOICS}

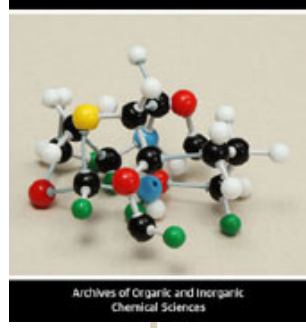

Archives of Organic and Inorganic Chemical Sciences

\section{Assets of Publishing with us}

- Global archiving of articles

- Immediate, unrestricted online access

- Rigorous Peer Review Process

- Authors Retain Copyrights

- Unique DOI for all articles 